\title{
Bax siRNA promotes survival of cultured and allografted granule cell precursors through blockade of caspase-3 cleavage
}

\author{
SS Zhokhov ${ }^{1,5}$, A Desfeux ${ }^{1,2,5}$, N Aubert ${ }^{1,3}$, A Falluel-Morel ${ }^{1}$, A Fournier ${ }^{4}$, V Laudenbach ${ }^{2}$, H Vaudry ${ }^{1}$ and BJ Gonzalez ${ }^{\star 1,2}$
}

Transplantation of neuronal precursor cells (NPCs) into the central nervous system could represent a powerful therapeutical tool against neurodegenerative diseases. Unfortunately, numerous NPCs die shortly after transplantation, predominantly due to caspase-dependent apoptosis. Using a culture of cerebellar neuronal precursors, we have previously demonstrated protective effect of the neuropeptide PACAP, which suppresses ceramide-induced apoptosis by blockade of the mitochondrial apoptotic pathway. The main objective of this study was to determine whether Bax repression can promote survival of NPCs allotransplanted into a host animal. In vivo and ex vivo experiments revealed that C2-ceramide increases Bax expression, while PACAP reverses this effect. In vitro tests using cerebellar NPCs demonstrated that the Bax-specific small interfering RNA (siRNA) could reduce their death and caspase-3 cleavage within the first $24 \mathrm{~h}$. BrdU-labelled NPCs were subjected to transfection procedure with or without siRNA introduction before using for in vivo transplantation. Twenty-four hours after, the allografted NPCs containing siRNA showed significantly reduced level of caspase-3 cleavage, and the volume of their implants was almost twofold higher than in the case of empty-transfected precursors. These data evidence an important role of Bax in life/death decision of grafted NPCs and suggest that RNA interference strategy may be applicable for maintaining NPCs survival within the critical first hours after their transplantation.

Cell Death and Differentiation (2008) 15, 1042-1053; doi:10.1038/cdd.2008.29; published online 7 March 2008

Programmed cell death, or apoptosis, plays a crucial role in a number of physiological and pathological processes taking place in the nervous system, such as neurodevelopment and neurodegenerative diseases. ${ }^{1,2}$ The intracellular pathways of apoptosis are numerous, but they are extremely well conserved among different cell types and animal species. ${ }^{3}$ In particular, several apoptotic pathways have been found to be dependent on caspases, the members of a cysteine proteases family. For example, caspase-8, which can be activated via TNF- $\alpha$ family receptors, is linked with the extrinsic apoptotic pathway. At the same time, caspase- 9 is involved in the mitochondrial-dependent apoptotic pathway. The mitochondrial integrity, which is disrupted upon activation of this latter pathway, is controlled by $\mathrm{Bcl}-2$ family proteins. ${ }^{4}$ Members of this family include both pro- and anti-apoptotic proteins: the ratio between these two subsets determines, in part, the susceptibility of cells to death signals. ${ }^{5}$ Activation of the pro-apoptotic protein Bax leads to its subcellular translocation to the mitochondria, where its dimerization causes permeabilization of the outer mitochondrial membrane and, in turn, the release of numerous proteins from the intermembrane space. ${ }^{6}$ A common terminal point has been found for both extrinsic and mitochondrial-dependent apoptotic pathways. It is represented by the executioner caspase $-3,{ }^{7}$ which is clearly implicated in the development of the central nervous system. The disruption of some caspase-encoding genes, including those for caspases 1,3 , and 9, may result in severe cell death abnormalities. ${ }^{8,9}$ Nevertheless, the knockout mice lacking some of these genes may exhibit different phenotypes: this suggests that various apoptotic pathways can be activated in different cell types or tissues.

The pituitary adenylate cyclase-activating peptide (PACAP) is a neuropeptide discovered in 1989 that belongs to the vasoactive intestinal polypeptide superfamily. Two forms of PACAP with 27- and 38-amino acid residues have been characterized and possess similar biological activities. ${ }^{10} \mathrm{We}$ have previously shown that this peptide exhibits antiapoptotic effects on the primary cultures of cerebellar granule neurons. In particular, it acts as a potent inhibitor of Bax expression when it is induced by ceramides, agents acting as

\footnotetext{
${ }^{1}$ INSERM U413, Laboratory of Cellular and Molecular Neuroendocrinology, Laboratoire International Associé Samuel de Champlain, European Institute for Peptide

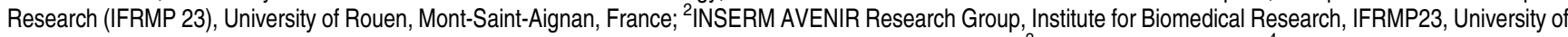
Rouen \& Department of Neonatal Paediatrics and Intensive Care, Rouen University Hospital, Rouen, France; ${ }^{3} \mathrm{CIT}$, Evreux, France and ${ }^{4}$ INRS-Institut Armand-Frappier, University of Québec, Pointe-Claire, PQ, Canada

*Corresponding author: BJ Gonzalez, INSERM Avenir, Mechanisms and treatments of developmental cerebral disorders, Rouen Institute for Biomedical Research, European Institute for Peptide Research (IFRMP 23), University of Rouen, Mont-Saint-Aignan 76821, France. Tel: + 33235148547 ; Fax: + 33 235 14 83 56; E-mail: bruno.gonzales@univ-rouen.fr

${ }^{5}$ These two authors contributed equally to this work

Keywords: pituitary adenylate cyclase-activating polypeptide; neuronal apoptosis; cerebellum; allotransplantation; mitochondrial apoptotic pathway; RNA interference Abbreviations: BrdU, 5-bromo-2-deoxyuridine; CNS, central nervous system; DAB, 3,3'-diaminobenzidine; DAPI, 4',6-diamidino-2-phenylindole; FDA, fluoresceine diacetate; GFP, green fluorescent protein; NPC, neuronal precursor cell; PACAP, pituitary adenylate cyclase-activating peptide; ROI, region of interest; siRNA, small interfering RNA

Received 28.5.07; revised 14.1.08; accepted 01.2.08; Edited by N Bazan; published online 07.3.08
} 
pro-apoptotic factors in these cells. ${ }^{11}$ The MAP-kinase pathway appears to be essential for the antiapoptotic effect of PACAP. Besides that, recent data have shown that the PACAP-induced blockade of Bax is mediated by ERK activation. ${ }^{11,12}$ Ceramides, the metabolites of sphingomyelin, represent important signalling molecules and play crucial roles during neuronal development. ${ }^{13}$ They are involved in the regulation of neuronal plasticity, axonogenesis, and cell death. In particular, ceramides have been shown to induce Bax gene expression via JNK-dependent pathway in different cell types. ${ }^{11,14}$ Altogether, these results obtained in vitro suggest that apoptosis of cultured granule neurons occurs primarily through activation of the mitochondrial-dependent apoptotic pathway. In addition, the mentioned data may lead to a hypothesis that Bax represents the primary target for both PACAP and ceramides. Nevertheless, no studies have been performed up to now which could demonstrate that similar effects of PACAP and ceramides are also exhibited in vivo, and cerebellar neuronal precursors could thus be protected from degeneration in vivo by the inhibition of Bax expression.

The therapeutical transplantation of neuronal precursor cells (NPCs) is a promising strategy for the treatment of several neurodegenerative pathologies and CNS injuries, as far as transplanted cells may replace lost or dysfunctional host cells. ${ }^{15}$ However, a substantial loss of grafted cells usually occurs within the first hours following the transplantation. ${ }^{16}$ Because of this, these newly introduced neurons have very low potential to integrate into the neurite network of the recipient. There are some literature data which suggest that the caspase-dependent apoptosis is a predominant reason of neural graft death. ${ }^{16,17}$ At the same time, it has not yet been tested whether or not such apoptosis occurs by the mitochondrial-dependent pathway. Based on our previous results, we have hypothesized that Bax-induced activation of the mitochondrial apoptotic pathway is a major event, which leads to death of granule cell precursors after their transplantation. In this case, the suppression of the gene encoding Bax should promote survival of those cells and, moreover, this effect should be inducible by PACAP.

In the present report, we have investigated the regulatory effects of C2-ceramide and PACAP on Bax expression in vivo and ex vivo. We have also studied the influence of Bax suppression on the apoptosis of cerebellar granule cell precursors using RNA interference and allografting strategies.

\section{Results}

Effects of C2-ceramide and PACAP on Bax expression by cerebellar granule cell precursors ex vivo and in vivo. Bax protein expression by the cells of 8-day-old rat cerebellum was determined by immunohistochemistry. In control group containing non-injected animals, the most of Bax-positive cells were observed at the levels of granule and Purkinje cell layers (Figure 1a). Omission of anti-Bax primary antibodies resulted in disappearance of immunolabelling (Figure $1 \mathrm{~b})$. The injection of saline $(0.9 \% \mathrm{NaCl})$ into the cerebellum did not affect Bax-specific immunoreactivity (Figure 1c and d). The injection of C2-ceramide $(40 \mu \mathrm{M})$ caused a strong local increase in Bax-specific immunoreactivity nearby the injection site, where a strong alteration of cell morphology could also be observed (Figure $1 \mathrm{e}$ and $\mathrm{f}$ ). The quantification of $\mathrm{C2}$-ceramide-induced Bax expression was performed using the technique of cerebellar organotypic slices and western blotting (Figure $1 \mathrm{~g}$ and $\mathrm{h}$ ). The tissues were incubated during $4 \mathrm{~h}$ with $\mathrm{C} 2$-ceramide (20 and $40 \mu \mathrm{M})$ and/or PACAP $\left(10^{-7} \mathrm{M}\right)$. PACAP administered alone caused slight and not significant decrease in Bax protein level (Figure $1 \mathrm{~g}$ and $\mathrm{h}$ ). Unlike that, C2-ceramide $(40 \mu \mathrm{M})$ significantly increased Bax expression (Figure $1 \mathrm{~g}$ and $\mathrm{h} ; P<0.05)$. When coincubated, PACAP prevented the stimulatory effect of $\mathrm{C} 2$-ceramide $(40 \mu \mathrm{M})$ on Bax expression (Figure $1 \mathrm{~g}$ and $\mathrm{h} ; P<0.05$ ).

Effects of Bax repression by small interfering RNAs on the survival of cultured cerebellar granule cell precursors and activity of caspase-3. To evaluate the effect of Bax repression on survival of neuronal precursors in vitro, these cells were transfected by one of two specific siRNAs interacting with Bax mRNA. Bax protein level was then measured using western blot approach (Figure $2 \mathrm{a}$ and b). In the control (non-transfected) cells, relatively high levels of Bax were detected after 6 and $12 \mathrm{~h}$ of cultivation (Figure $2 \mathrm{a}$ and $\mathrm{b}$ ); the maximum was reached at $12 \mathrm{~h}$ (Figure 2c; $P<0.05)$. In the cells transfected without any siRNA, socalled 'empty-transfected' cells, the maximal Bax expression has been registered at $6 \mathrm{~h}$ (Figure $2 \mathrm{a}$ and $\mathrm{c}$ ). Both siBax-1 and -2 significantly diminished Bax expression level in comparison to the empty-transfected cells. At $6 \mathrm{~h}$, the effect of siBax-1 appeared to be more pronounced than that of siBax-2 (Figure 2b; $P<0.05$ ). Twelve hours after transfection, Bax expression in cells transfected by siBax-2 was only slightly detectable; about $10-15 \%$ of the control level was remained (Figure $2 \mathrm{~b} ; P<0.01$ ).

The activity of caspase- 3 in the cells was measured using fluorometry in 6,12 , and $24 \mathrm{~h}$ of cultivation. The results are shown on Figure 3. A transient elevation of caspase-3 activity was observed in empty-transfected cells relatively to nontransfected ones; its maximal increase was at $6 \mathrm{~h}$ (Figure 3a; $P<0.05)$, following by progressive decrease up to 12 and $24 \mathrm{~h}$ (Figure $3 \mathrm{~b}$ and $\mathrm{c}$ ). Both siBax-1 and siBax-2 markedly reduced the caspase- 3 activity in comparison to the cells transfected without siRNA. However, a statistical significance level was only reached in 6 and 24 , but not in $12 \mathrm{~h}$ after transfection (Figure $3 \mathrm{~b}$ and $\mathrm{c} ; P<0.05$ ). The effects of both siRNAs were approximately equivalent at all analyzed time points.

The effects of Bax-specific siRNAs on cell survival were investigated by both qualitative and quantitative tests. The life/ death visualization was performed in $24 \mathrm{~h}$ of cultivation after transfection, when living cells were labelled with calcein (green fluorescence), and the nuclei of dead cells were marked with ethidium homodimer (orange fluorescence; Figure 4a-d). In non-transfected cultures, the majority of cells stayed alive and showed morphology typical for cerebellar granule cells with fusiform and bipolar cell bodies (Figure 4a). In empty-transfected cultures, numerous neurons were died and therefore labelled by ethidium homodimer (Figure 4b). Both siBax-1 and -2 markedly reduced the number of dead cells, which, however, was still more than in non-transfected cultures (Figure 4c and d). 

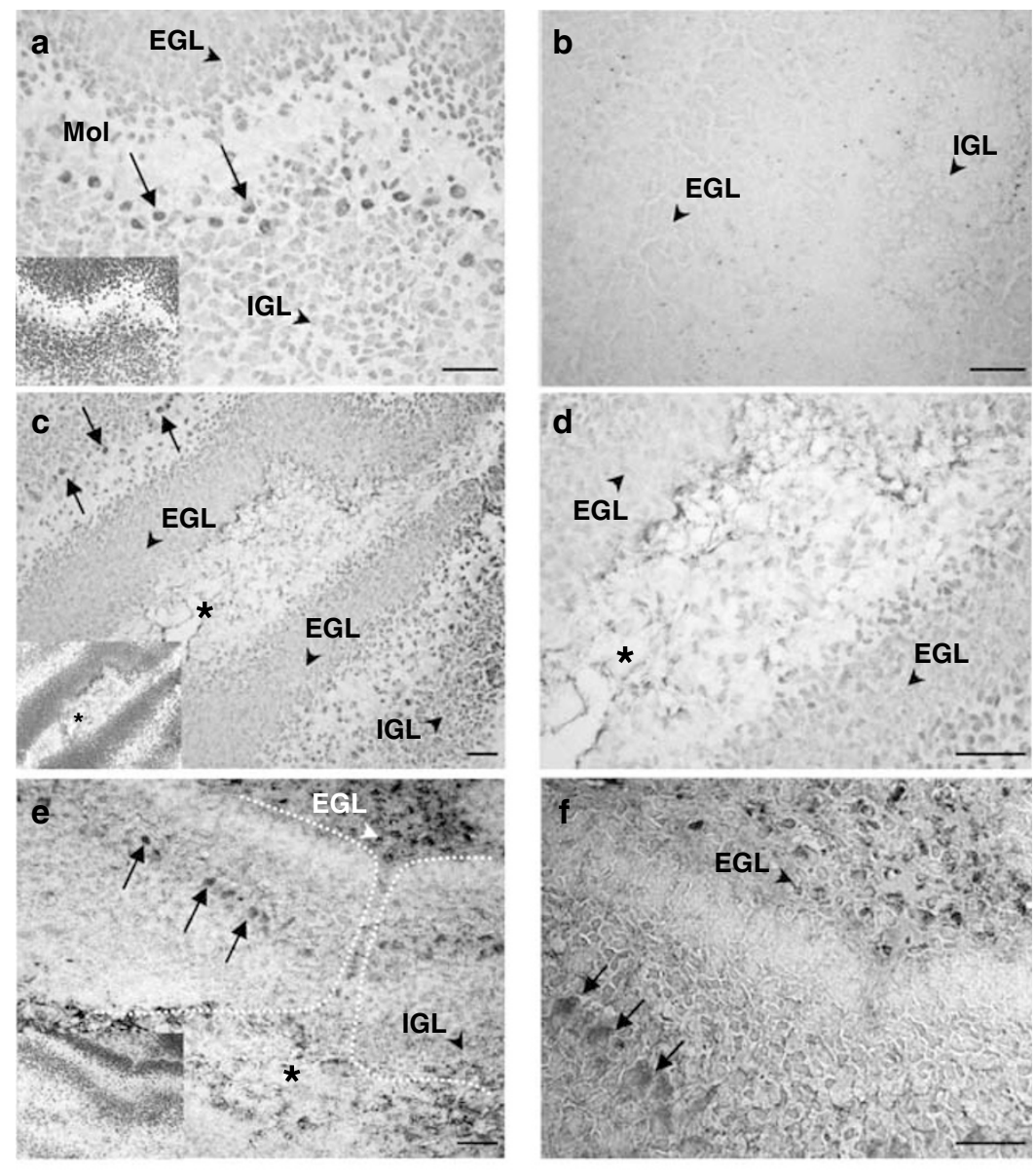

g

h
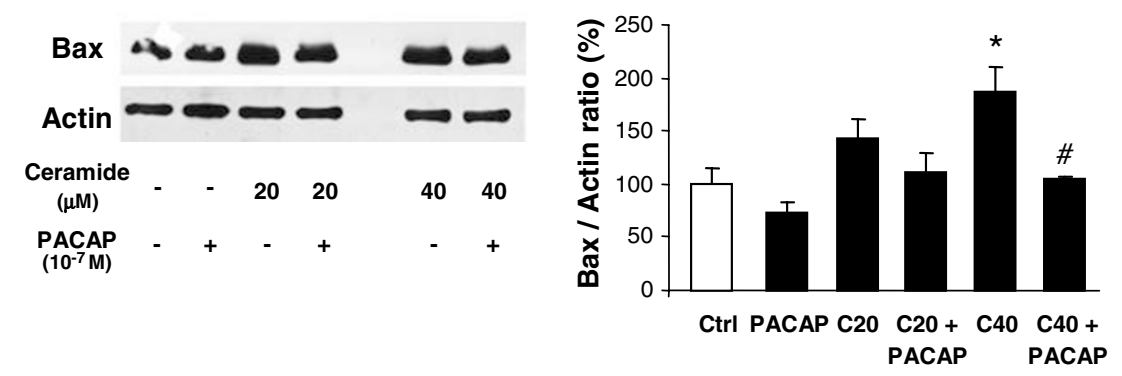

Figure 1 Effects of C2-ceramide and/or PACAP on Bax expression level in 8-day-old cerebellar neurons in vivo and in cerebellar organotypic slices. (a) Visualization of Bax immunostaining in a normal (control) cerebellum. (b) Negative control obtained by a similar immunostaining procedure without anti-Bax antibodies. (c and d) Bax-specific immunostaining in $4 \mathrm{~h}$ after intracerebellar injection of $0.9 \% \mathrm{NaCl}$; two different magnifications. (e and f) Bax immunostaining in $4 \mathrm{~h}$ after intracerebellar injection of $\mathrm{C2}$ ceramide $(40 \mu \mathrm{M})$ in $0.9 \% \mathrm{NaCl}$; two different magnifications. (g) Western blot analysis of Bax expression in cerebellar organotypic slices incubated with C2-ceramide (20 or $40 \mu \mathrm{M})$ and/or PACAP $\left(10^{-7} \mathrm{M}\right.$ ) during $4 \mathrm{~h}$. (h) Quantification of western blot results presented as Bax/actin ratio. Each value represents the mean ( \pm S.E.M.) of three independent experiments performed in duplicate. Insertions visualize the corresponding Cresyl violet staining of the slices used for Bax immunohistochemistry. Arrowheads indicate different cerebellar layers. Arrows indicate Bax immunoreactive cells in the cerebellar cortex; asterisks and dotted lines indicate the injection point site. EGL: external granule cell layer; IGL: internal granule cell layer; Mol: Molecular layer. Scale bars represent $25 \mu \mathrm{m}$. ${ }^{*} P<0.05$ versus control; ${ }^{\#} P<0.05$ versus samples treated by $40 \mu \mathrm{M}$ C2ceramide

The results of cell death quantification were in accordance with those data. The number of living cells in empty-transfected culture after $6 \mathrm{~h}$ of its cultivation was $40 \%$ less than in non-transfected culture (Figure $4 \mathrm{e}$ ). The percentage of dead neurons in empty-transfected cultures became even more increased after 12 or $24 \mathrm{~h}$ of cultivation (50 and $60 \%$, respectively; Figure $4 \mathrm{e}$ ). No survival stimulation by either siBax-1 or siBax-2 has been observed in $6 \mathrm{~h}$ after transfection, while in 12 and $24 \mathrm{~h}$ both siRNAs revealed strong and significant survivalpromoting effect (Figure 4e; $P<0.05 ; P<0.01$ ). It should be noted that in $24 \mathrm{~h}$, that is, at the latest analyzed time point, the 

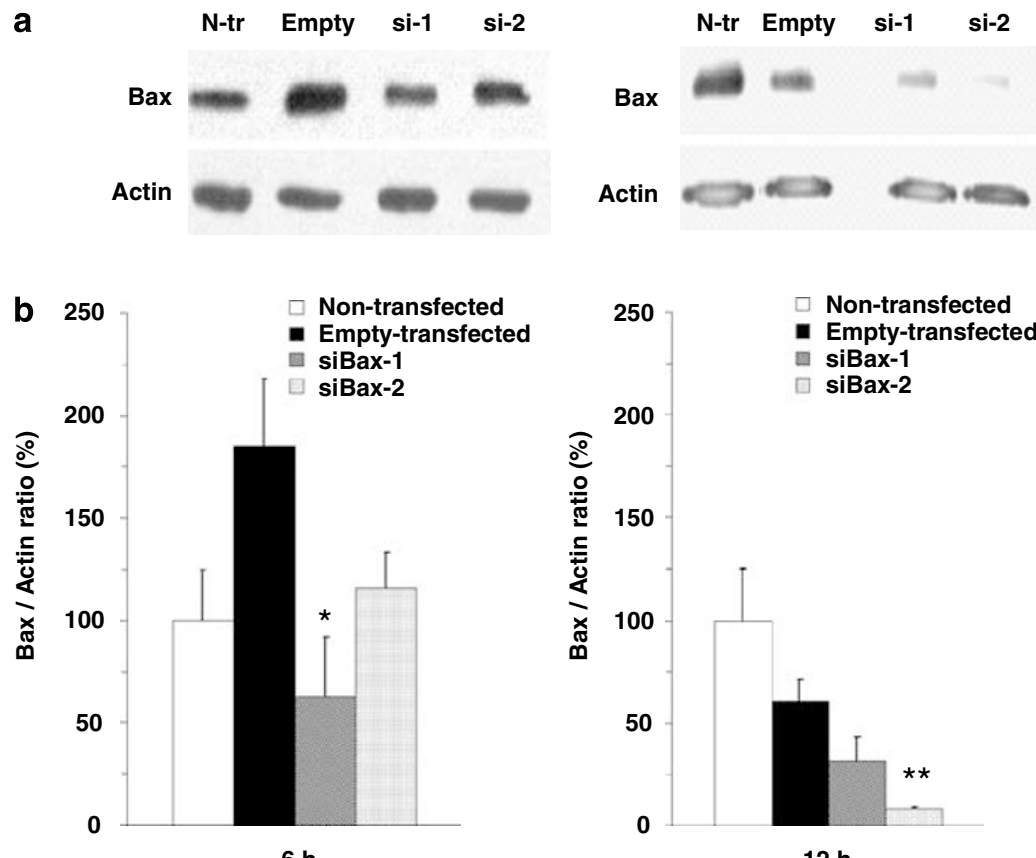

C
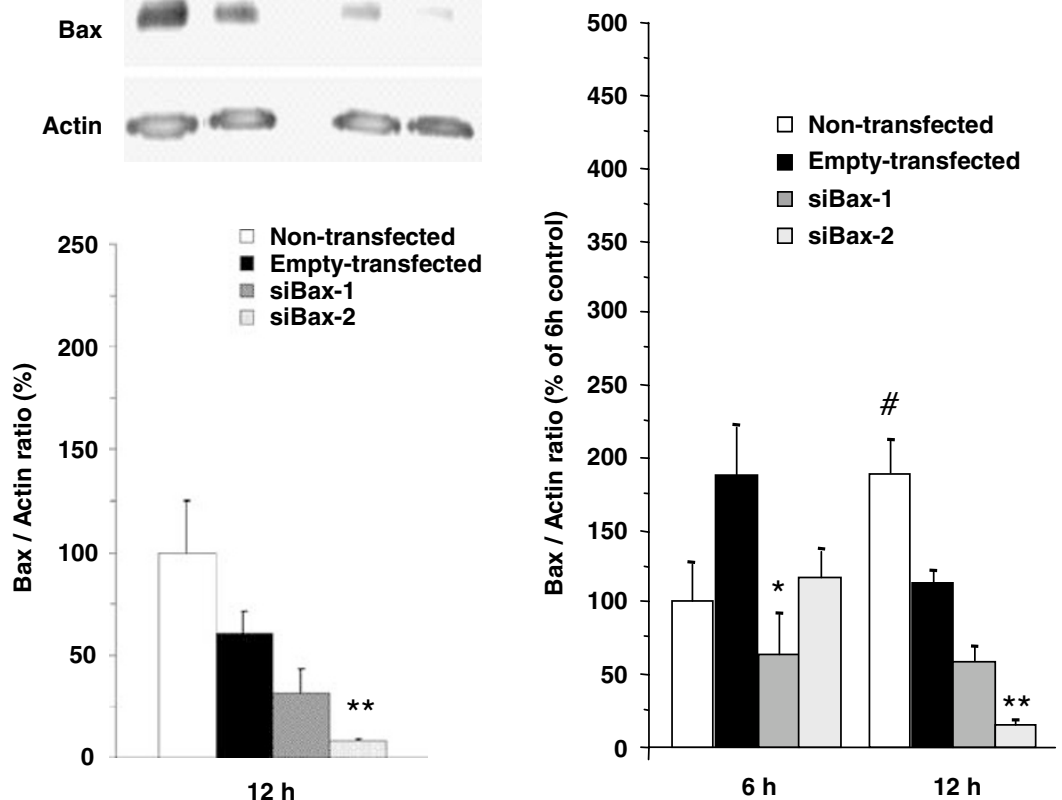

Figure 2 Effect of Bax-specific siRNAs, siBax-1 and siBax-2, on Bax protein expression in cultured cerebellar granule neuronal precursors. (a) Visualization of Bax and actin levels by western blot in 6 and $12 \mathrm{~h}$ after transfection of cells with siBax-1 or siBax-2. Actin is used as an internal control. (b) Quantification of western blot data. Results are normalized and presented as Bax/actin ratio. (c) Bax expression levels normalized to non-transfected cells cultivated for 6 h. Each value represents the mean ( \pm S.E.M.) of three independent experiments performed in duplicate. ${ }^{*} P<0.05$; ${ }^{* *} P<0.01$ versus empty-transfected cells. ${ }^{\#} P<0.05$ versus non-transfected cells cultivated for $6 \mathrm{~h}$. N-tr: non-transfected neurons; Empty: neurons subjected to the transfection without any siRNA (empty-transfected); siBax-1, siBax-2: neurons subjected to the transfection with siBax-1 and siBax-2, respectively
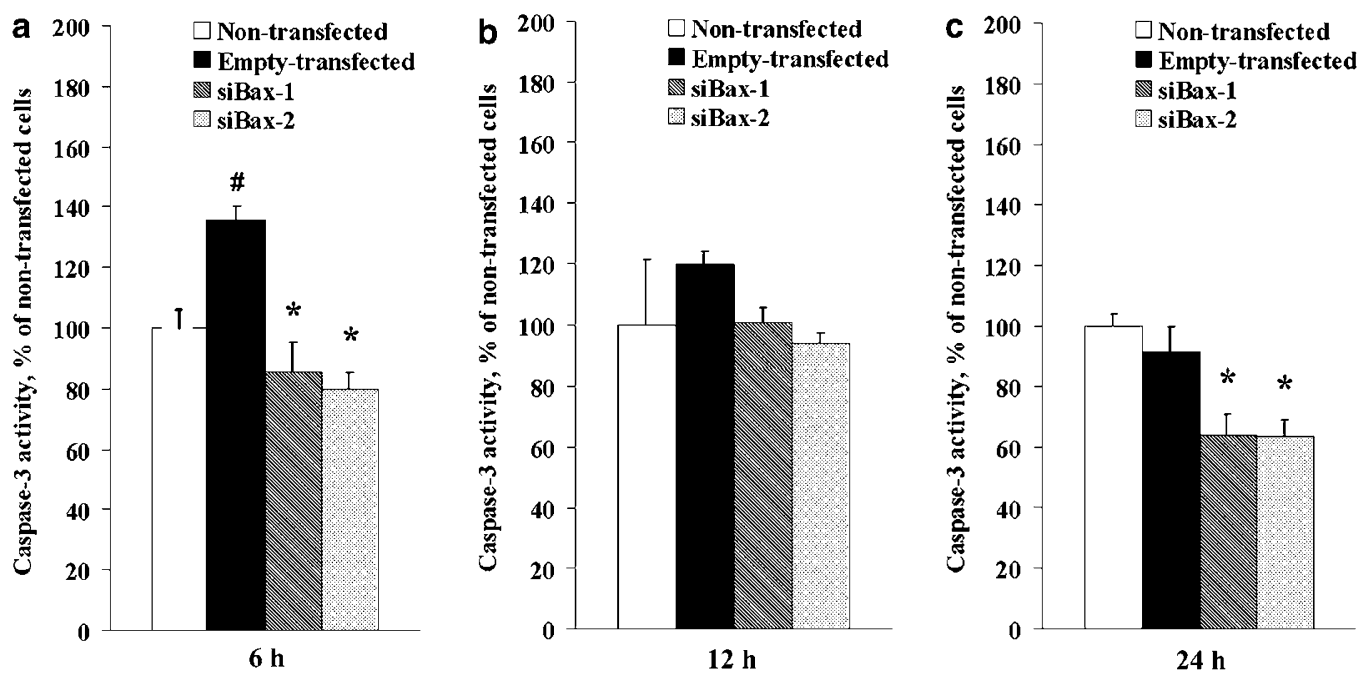

Figure 3 Time-course effect of Bax siRNAs on caspase-3 activity in the cultures of cerebellar granule neuronal precursors. Caspase-3 activity was quantified: (a) in 6, (b) in 12 , (c) in $24 \mathrm{~h}$ of cultivation after transfection. Each value represents the mean ( \pm S.E.M.) of at least three independent experiments performed in triplicate. ${ }^{\#} P<0.05$ versus non-transfected cells; ${ }^{*} P<0.05$ versus empty-transfected cells. siBax-1, siBax-2: neurons subjected to the transfection with siBax-1 and siBax-2, respectively

survival stimulating effect of siBax-2 was stronger than that of siBax-1.

Effect of Bax gene suppression on the viability of transplanted neuronal precursor cells in vivo and caspase-3 cleavage. First, the mode of NPC transplantation into the cerebellum was optimized by the series of intracranial injections of Trypan blue solution into 8day-old rats (Figure $5 \mathrm{a}-\mathrm{c}$ ). For making grafted neurons easily distinguishable from the host ones, the nuclei of transplanted NPCs were previously labelled by BrdU. Pilot studies revealed that in $6 \mathrm{~h}$ after BrdU injection almost all 

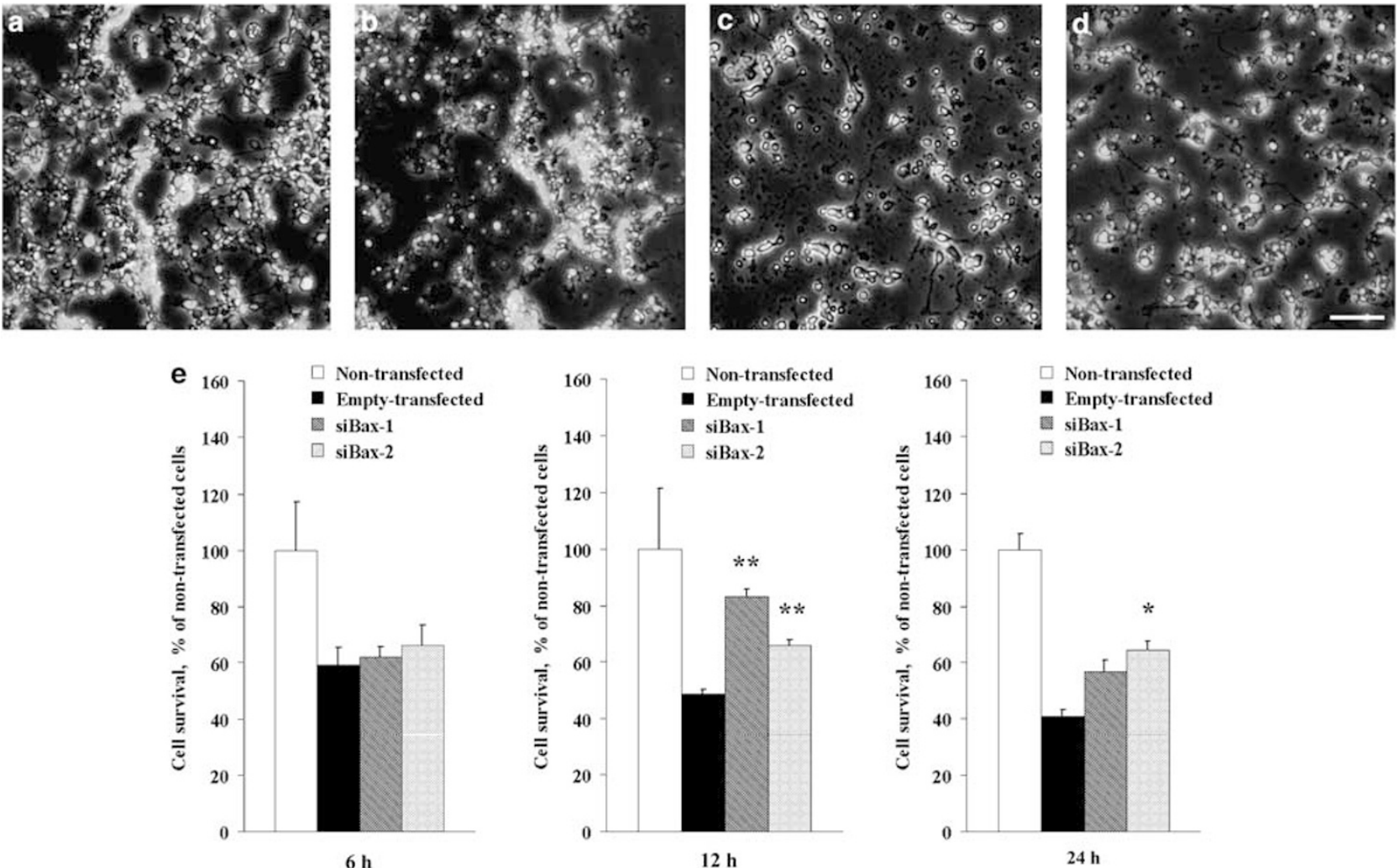

Figure 4 Effect of Bax siRNAs on survival of cerebellar granule neuronal precursors. (a-d) Images of primary cultures (in $24 \mathrm{~h}$ after transfection) treated by calcein/ ethidium homodimer demonstrating cell survival and death in primary cultures after this time period. (a) Non-transfected neurons (control); (b) neurons transfected without siRNA (empty-transfected); (c) neurons transfected by siBax-1; (d) neurons transfected by siBax-2. Images are presented as overlays of green (living cells) and orange (dead cells) fluorescences. (e) Quantification of granule cell survival in primary cultures in 6, 12, and $24 \mathrm{~h}$ after transfection with or without Bax siRNA. Each value represents the mean $\left( \pm\right.$ S.E.M.) of three independent experiments performed in triplicate. ${ }^{*} P<0.05 ;{ }^{\star *} P<0.01$ versus empty-transfected cells. Scale bar represents $50 \mu \mathrm{m}$. siBax-1, siBax2: neurons subjected to the transfection with siBax-1 and siBax-2, respectively. A colour version of this Figure is available online

cerebellar progenitors in the external granule cell layer display BrdU-positive immunohistochemical staining (Figure 5d). Such BrdU-positive precursors were used for allotransplantation. A subsequent staining of cerebellar slices with Cresyl violet confirmed the presence of numerous cells into the graft area (Figure 5e). To visualize the shape of transplanted precursors, we have transfected them before transplantation by the plasmid expressing green fluorescent protein (GFP). The grafted cells had a round shape with sometimes one or two neurites (Figure $5 f$ and g). Twenty-four hours after transplantation of BrdU-labelled neurons into the cerebellum of host animal, a single zone of BrdU-positive cells could be observed on several histological slices of this cerebellum (Figure $5 \mathrm{~h}$ and $\mathrm{i}$ ).

The visualization of BrdU and cleaved caspase-3 in transplanted cells was performed by immunohistochemistry of adjacent cerebellar slices (Figure 6a-f). The grafted precursors could be easily identified by an intense BrdU signal. On Figure $6 \mathrm{a}$, which corresponds to the nontransfected grafts, this signal is marked by asterisk. The same cells also showed an immunoreactive staining corresponding to the cleaved caspase-3 (Figure 6b; arrows). Besides that, some cells immunoreactive with anticleaved caspase-3 antibodies were also visible in cerebellar lobules at the level of internal granule cell layer (Figure 6b; arrowheads).
The grafts in cerebella transplanted by empty-transfected precursors displayed a strong signal corresponding to the cleaved caspase-3 (Figure 6c and d; arrows). In contrast, when neuronal precursors transfected with siBax-2 were grafted, only a slight immunoreactivity with antibodies specific to cleaved caspase- 3 has been found in the BrdU-positive structures (Figure 6e and f; asterisks). However, a cleaved caspase-3 immunoreactivity, was still detectable in normal host neurons in cerebellar lobules (Figure 6e and f; arrowheads).

Fluorescent double-labelling experiments using cleaved caspase-3 and BrdU antibodies confirmed the intense cleaved caspase- 3 immunoreactivity present in the grafts realized with empty-transfected precursors (Figure $7 a$ and $b$ ). Inserts visualized different controls of specificity consisting in: (i) pre-incubation of the cleaved caspase- 3 antibody with its blocking peptide, (ii) replacement of the primary antibody by phosphate-buffered saline (PBS) and (iii) BrdU immunohistochemistry performed in animals uninjected with BrdU (Figure $7 \mathrm{a}$ and $\mathrm{b}$ ). In addition, the BrdU-positive immunoreactivity strictly overlapped with DAPI, a result that confirmed the nucleic origin of the BrdU labelling (Figure 7c-e; arrows). At high magnification, the cleaved caspase- 3 signal observed in empty-transfected cells was mainly cytosolic (Figure 7f). Some of these cells were also BrdU-positive (Figure 7f-h; 
arrows). In precursors transfected with siBax-2, the fluorescence associated with the cleaved caspase-3 immunoreactivity was low and numerous BrdU-positive cells were cleaved caspase-3-negative (Figure 7i-k; arrows). The fluorescent probe Celltracker $^{\mathrm{TM}}$ red was also used to visualize the grafted precursors (Figure $7 \mathrm{I}-\mathrm{t}$ ). In the empty-transfected condition, numerous Celltracker ${ }^{\mathrm{TM}}$ red-positive precursors were also cleaved caspase-3 immunoreactive (Figure 7I-n; arrows). In contrast, in animals injected with siBax-2 transfected cells, numerous precursors were Celltracker ${ }^{\mathrm{TM}}$ red-positive and cleaved caspase-3-negative (Figure 7o-q; arrowheads). Interestingly, even if they were scarce, some granule cell precursors transfected with siBax-2 presented small neurites (Figure 7r-t; arrows)

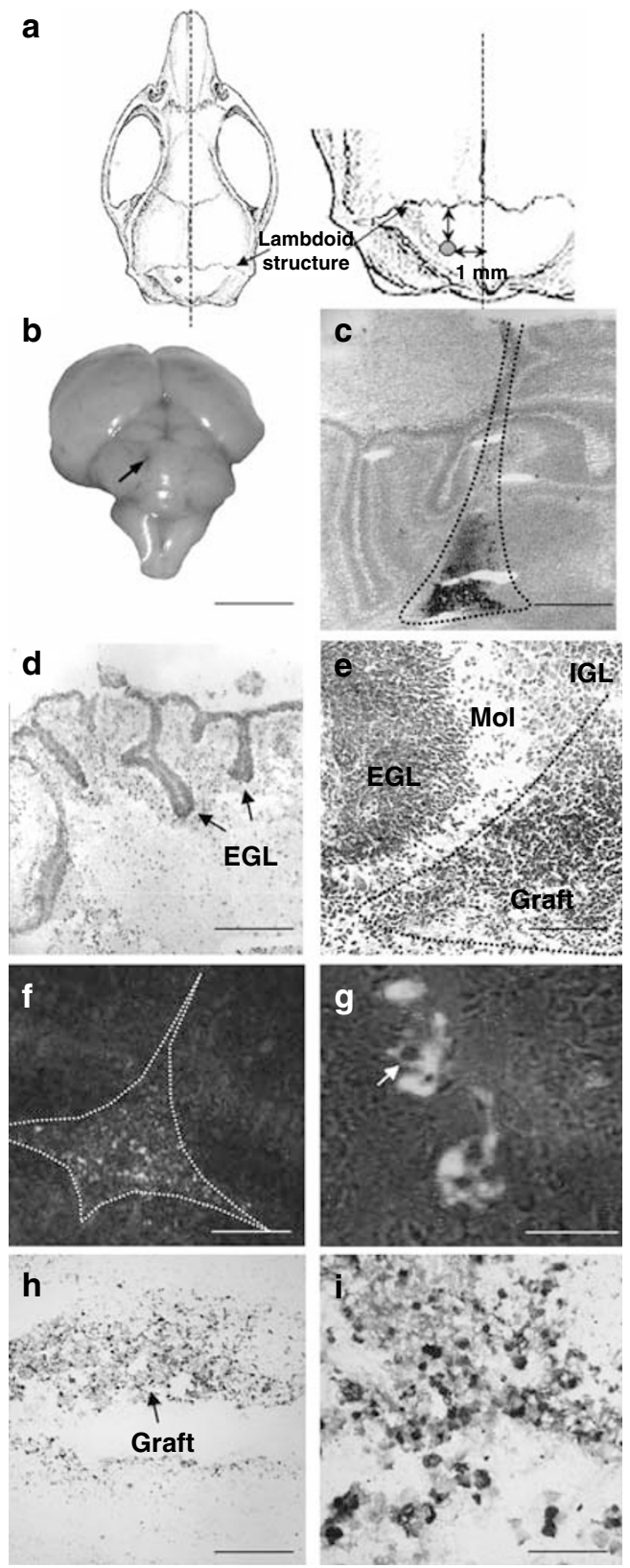

Graft volumes were quantified and visualized by 3D reconstruction. The average size of grafts in animals injected by empty-transfected precursors was obviously decreased in comparison with other groups (Figure $8 a$ and $b$ ). On the contrary, in the animals injected by precursors transfected with siBax-2, the graft volume was maximal (Figure $8 \mathrm{~b}$; $P<0.01$ ). To prevent a biased quantification due to cell loss during precursor injections, the grafts illustrated in Figure 6 were also analyzed using a stereologic and ratiometric quantification of structures revealing BrdU- and cleaved caspase-3-positive signals (Figure $8 \mathrm{c}-\mathrm{e}$ ). Twenty-four hours after precursor transplantation, the density of BrdU-positive structures was practically the same for all three groups (Figure 8c). At the same time, the cleaved caspase-3 immunoreactivity per $100 \mu \mathrm{m}^{2}$ of grafted zone was significantly higher in animals transplanted by empty-transfected precursors (Figure $8 \mathrm{~d} ; P<0.001$ ). In animals injected by precursors transfected with siBax-2, caspase-3 cleavage was much lower than in control group animals. (Figure 8d; $P<0.001)$. The ratiometric correction of these data confirmed the observation that siBax-2, being introduced into the precursors, significantly increases the BrdU/cleaved caspase-3 ratio in comparison to the case of empty-transfected cells (Figure $8 \mathrm{e} ; P<0.01$ ). Cleaved caspase-3 immunoreactivity was also related to a Celltracker ${ }^{\mathrm{TM}}$ red colabelling index (Figure $8 \mathrm{f}-\mathrm{h}$ ). After segmentation of the Celltracker ${ }^{\mathrm{TM}}$ redpositive structures by using the fluorescence intensity profile of the image (Figure $8 f$ and $g$ ), cleaved caspase-3 immunoreactivity was quantified into the region of interest (ROI; Figure 8h). As visualized in figure $7 \mathrm{I}-\mathrm{n}$, in the emptytransfected condition, the proportion of Celltracker ${ }^{\mathrm{TM}}$ redpositive cells colabelled with the cleaved caspase- 3 antibody was significantly increased when compared to the control condition (Figure 8h; $P<0.01$ ). In contrast, the percentage of colabelling was markedly reduced when precursors were transfected by siBax-2 prior injection into the host animal (Figure 8h; $P<0.01$ ).
Figure 5 Standardization of injection mode used for allografting of granule cell precursors into the cerebellum of 8-day-old rats. (a) Injection point position corresponding to the following stereotaxic coordinates relatively to the lambda structure: $A P=1 \mathrm{~mm}, \mathrm{~L}=1 \mathrm{~mm}, \mathrm{DV}=3 \mathrm{~mm}$. (b) Visualization of the injection point at the cerebellum surface using trypan blue solution. Scale bar represents $5 \mathrm{~mm}$. (c) Histological section visualizing the cerebellar zone containing trypan blue solution after its injection. Scale bar represents $300 \mu \mathrm{m}$. (d) Visualization of BrdU incorporation into the EGL of 8-day-old rat cerebellum in $6 \mathrm{~h}$ after its administration. Scale bar represents $300 \mu \mathrm{m}$. (e) Cresyl violet staining of grafted granule cell precursors in $24 \mathrm{~h}$ after their transplantation into the 8-day-old rat cerebellum. Scale bar represents $100 \mu \mathrm{m}$. (f) Visualization, at low magnification, of GFP-labelled grafted granule cell precursors $24 \mathrm{~h}$ after their transplantation into the 8-day-old rat cerebellum. Scale bar represents $100 \mu \mathrm{m}$. (g) Visualization, at high magnification, of GFP-labelled grafted granule cell precursors $24 \mathrm{~h}$ after their transplantation into the 8-day-old rat cerebellum. Arrow shows a bipolar cell. Scale bar represents $35 \mu \mathrm{m}$. (h) Visualization, at low magnification, of BrdU-positive grafted granule cell precursors $24 \mathrm{~h}$ after their transplantation into the 8-day-old rat cerebellum. Scale bar represents $100 \mu \mathrm{m}$. (i) Visualization, at high magnification, of BrdU-positive grafted granule cell precursors $24 \mathrm{~h}$ after their transplantation into the 8-day-old rat cerebellum. Scale bar represents $50 \mu \mathrm{m}$. Dotted lines indicate the zones containing grafted precursors. EGL: external granule cell layer; IGL: internal granule cell layer; Mol: Molecular layer 

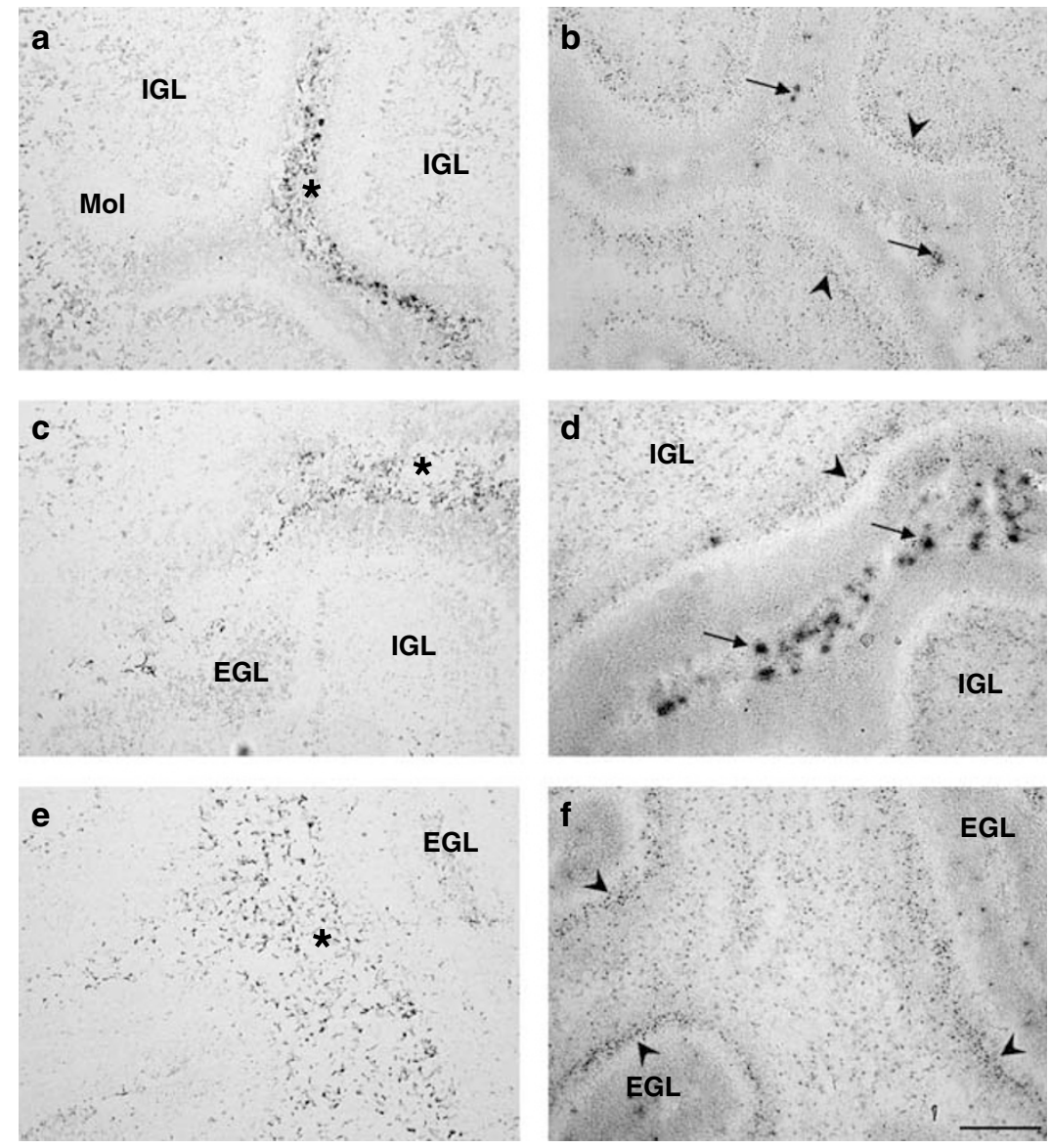

Figure 6 Visualization of BrdU and cleaved caspase-3 immunoreactivity in the grafted granule cell precursors. (a, $\mathbf{c}$ and $\mathbf{e})$ BrdU-immunostaining visualized in nontransfected (a), empty-transfected (c) and siBax-2-transfected (e) grafted cells in $24 \mathrm{~h}$ after their transplantation. (b, $\mathbf{d}$ and f) Cleaved caspase-3 immunostaining visualized in non-transfected (b), empty-transfected (d) and siBax-2-transfected (f) grafted cells $24 \mathrm{~h}$ after their transplantation, as well as in the host tissues. EGL: external granule cell layer; IGL: internal granule cell layer; Mol: Molecular layer. Asterisks: BrdU-positive grafted cells. Arrows: cleaved caspase-3 immunoreactivity in allografts. Arrowheads: cleaved caspase-3 immunoreactivity in host tissues. Scale bar represents $50 \mu \mathrm{m}$

\section{Discussion}

Ceramides, the sphingolipid-derived second messengers, are powerful apoptosis inductors in immature granule neurons. ${ }^{18}$ We have previously demonstrated that the ceramidesinduced apoptosis onto cerebellar neuronal precursors is completely abrogated by the neuropeptide PACAP. ${ }^{19}$ Caspases- 3 and -9 were found to be the main targets of PACAP neuroprotective action towards this cell type. ${ }^{11,12}$ Several apoptotic pathways have been found to be dependent on different caspases. For example, caspase-8, which can be activated via TNF- $\alpha$ family receptors, is associated with the extrinsic apoptotic pathway. At the same time, caspase- 9 is involved in the mitochondrial-dependent apoptotic pathway. Upon activation of this latter pathway, the mitochondrial integrity is disrupted and controlled by Bcl-2 family proteins. ${ }^{4}$ This family includes both pro- and antiapoptotic protein factors; a fine balance of their activation and suppression makes cells more or less sensitive to life and death signals. ${ }^{5}$ Several processes, such as alterations of expression level and phosphorylation state ${ }^{20,21}$ can shift the equilibrium imposed by the $\mathrm{Bcl}-2$ family members. In particular, modifications of their homo/heterodimerization may lead to mitochon- drial integrity disruption with release of intermembrane space proteins, such as cytochrome $c{ }^{6}$ Since ceramides and PACAP exert opposite effects on the pro-apoptotic gene Bax expression and, consequently, the protein release from mitochondria, ${ }^{11,12}$ we have raised a hypothesis that Bax, as mitochondrial apoptotic pathway activator, has a primary contribution into the apoptotic death of granule neuronal precursors. If so, the repression of Bax gene in these cells should favour their survival in a post-transplantational period.

A transient stimulation of Bax gene expression is associated with various pro-apoptotic stimuli, such as oxidative stress or excessive glutamate concentration. ${ }^{20}$ It is well established that, in vitro, C2-ceramide activates Bax expression in immature granule cells through the JNK-dependent mechanism. ${ }^{11}$ These data strongly suggest that such Bax stimulation is involved into the control of programmed cell death of these cells during CNS development. Consistent with this hypothesis, there are now several evidences that ceramides are important intracellular regulators of programmed cell death. ${ }^{22}$ In vitro studies revealed that some pro-inflammatory cytokines such as FasL and TNF- $\alpha$ induce neuronal apoptosis through sphingolipid cycle alteration, ${ }^{23}$ while, in vivo, a local ceramides production induced by 
irradiations leads to apoptosis of various tissues. ${ }^{24}$ Taken together, these observations suggest that FasL and/or TNF- $\alpha$ could induce neuronal apoptosis during neurodevelopment and also participate in the control of granule cell death through regulation of ceramides production. Consistent with this hypothesis, it has been shown that in vitro granule cell apoptosis was associated with an increase of the disialoganglioside GD3 and ceramides productions, and these effects were blocked by Fas receptor deactivation. ${ }^{25}$ Nevertheless, no experimental data were published up to now describing ceramides effects on Bax expression during cerebellar development in vivo. In the present study, we have shown that intracerebellar injections of C2-ceramide, a cell-permeable analogue of the endogenous ceramides, could induce Bax expression in cerebellar neurons of 8-day-old rats. In this case, Bax-positive immunostaining has mostly been detected in the granule cell precursors of the external granule cell level positioned near the injection point, since C2-ceramide had
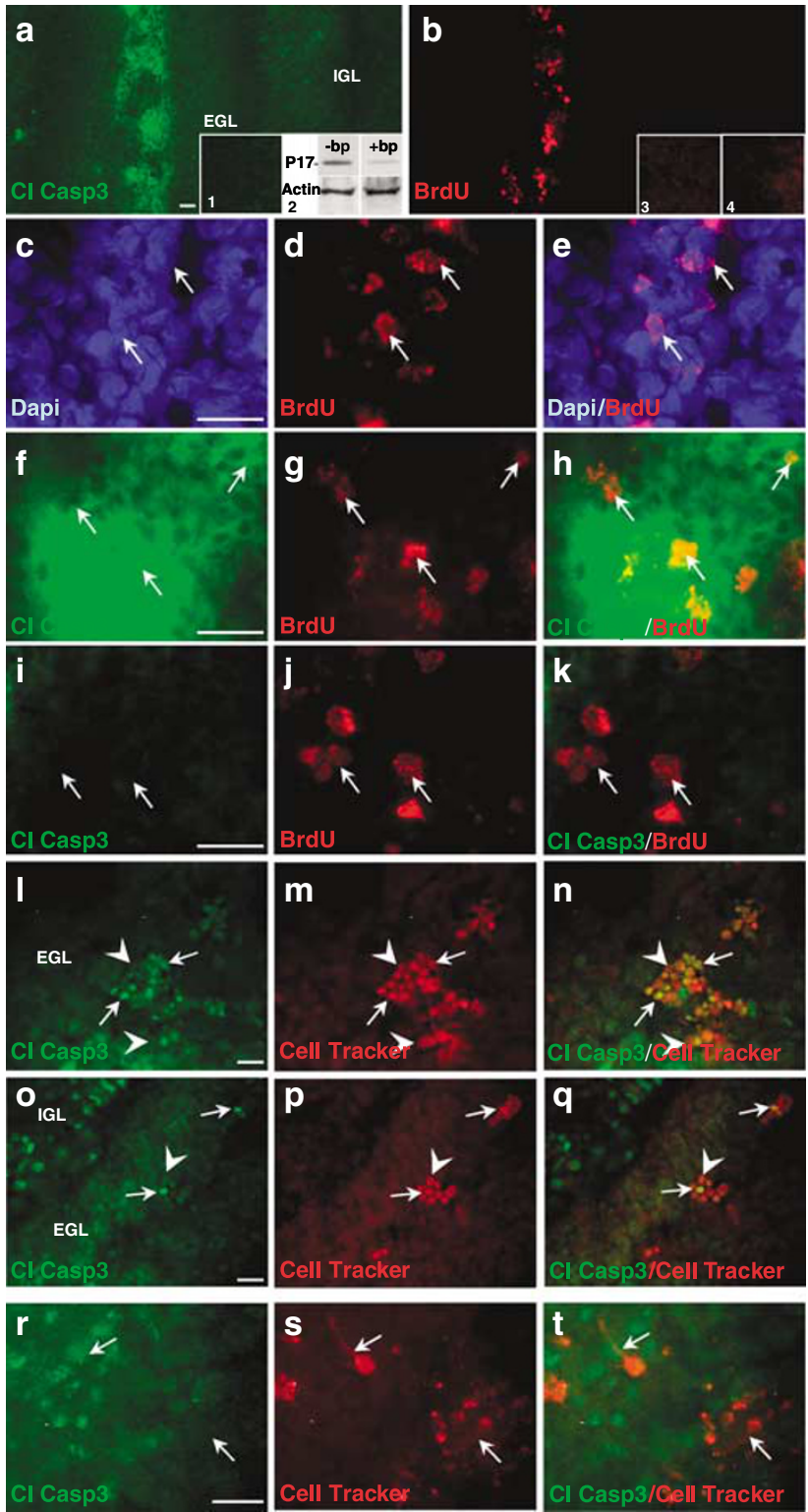

been introduced locally into a single specific site. We have quantified this effect by western blot of organotypic cerebellar slices and observed its blockage by the neuropeptide PACAP. Altogether, these data indicate that both ceramides and PACAP participate in a balanced control of Bax expression in granule cell precursors in vivo, as well as it has been previously shown in vitro.

For the propagation and accomplishment of apoptotic signals, the caspase-dependent and/or independent apoptotic pathways should be activated. Caspases, a family of cysteine proteases, can be activated through several pathways involving death factor receptors, mitochondria or endoplasmic reticulum. ${ }^{26}$ Nevertheless, different cell types may have a predominant apoptotic pathway. ${ }^{27}$ For example, rhabdomyosarcoma malignant tumours are particularly sensitive to Bax invalidation, while ovarian germ cells, depending on their maturity degree, shift from Bax-dependent to Baxindependent apoptosis. ${ }^{28,29}$ In the present study, we have found that siRNA-induced Bax suppression promotes survival of granule cell precursors. Concurrently, the activity of a transiently activated executioner caspase- 3 was also blocked by Bax repression. ${ }^{30,31}$ It should be noted that the previous studies on the knockout animals lacking Bax gene revealed only a reduction, but not a full blockade of cell death in the developing cerebellum. This suggests that various cells are differently sensitive to Bax inactivation. ${ }^{32}$ Taken together, these data indicate that Bax, acting as a caspase-3 stimulator, plays a key role in the control of apoptosis of granule cell precursors.

Neuronal precursors transplanted into the corresponding brain structure of a host animal (allotransplants) have a

Figure 7 Visualization of cleaved caspase-3, BrdU, DAPI and CellTracker ${ }^{\mathrm{TM}}$ Red labelling in the grafted granule cell precursors. (a and $\mathbf{b})$ Low magnification microphotographs illustrating the immunoreactivity of cleaved caspase-3 (a) and BrdU (b) in empty-transfected cells. Insertions: (1) immunoreaction obtained without the primary antibody. (2) western blot visualizing the $17 \mathrm{kDa}$ protein corresponding to the large cleaved caspase-3 fragment. The primary antibody was preincubated or not with the blocking peptide (bp). (3) immunoreactive signal obtained in animal uninjected with BrdU. (4) immunoreaction obtained without the primary antibody. (c-e) High magnification microphotographs visualizing the immunoreactivities for DAPI (c), BrdU (d) and the overlay of both signals (e). Arrows indicate DAPI and BrdU-positive nuclei. (f-h) High magnification microphotographs visualizing the immunoreactivities for cleaved caspase-3 (f), BrdU (g) and overlay of both signals (h) in empty - transfected grafted cells. Arrows indicate apoptotic cells positive for cleaved caspase-3 and BrdU. (i-k) High magnification microphotographs visualizing the immunoreactivities for cleaved caspase-3 (i), BrdU (j) and overlay of both signals (k) in siBax-2 transfected grafted cells. Arrows indicate cells negative for cleaved caspase-3 and positive for BrdU. (I-n) Microphotographs visualizing cleaved caspase-3 immunoreactivity (I), CellTracker ${ }^{\mathrm{TM}}$ Red labelling (m) and overlay of both signals ( $\mathbf{n}$ ) in empty transfected grafted cells. Arrows indicate cells positive for the cleaved caspase- 3 and the CellTracker ${ }^{\mathrm{TM}}$ Red. Arrowheads indicate cells negative for the cleaved caspase-3 and positive for the CellTracker ${ }^{\mathrm{TM}}$ Red. $(\mathbf{0}-\mathbf{q})$ Microphotographs visualizing cleaved caspase-3 immunoreactivity (o), CellTracker ${ }^{\mathrm{TM}}$ Red labelling (p) and overlay of both signals (q) in siBax-2-transfected grafted cells. Arrows indicate cells positive for the cleaved caspase-3 and the CellTracker ${ }^{\mathrm{TM}}$ Red. Arrowheads indicate cells negative for the cleaved caspase-3 and positive for the CellTracker ${ }^{\mathrm{TM}}$ Red. ( $\left.\mathbf{r}-\mathbf{t}\right)$ High magnification microphotographs visualizing the immunoreactivity for cleaved caspase-3 $(\mathbf{r})$, the CellTracker ${ }^{\text {TM }}$ Red labelling $(\mathbf{s})$ and overlay of both signals $(t)$ in siBax-2 transfected grafted cells. Arrows indicate CellTracker ${ }^{\mathrm{TM}}$ Red-positive cells presenting small neurites. Scale bar represents $25 \mu \mathrm{m}$ 

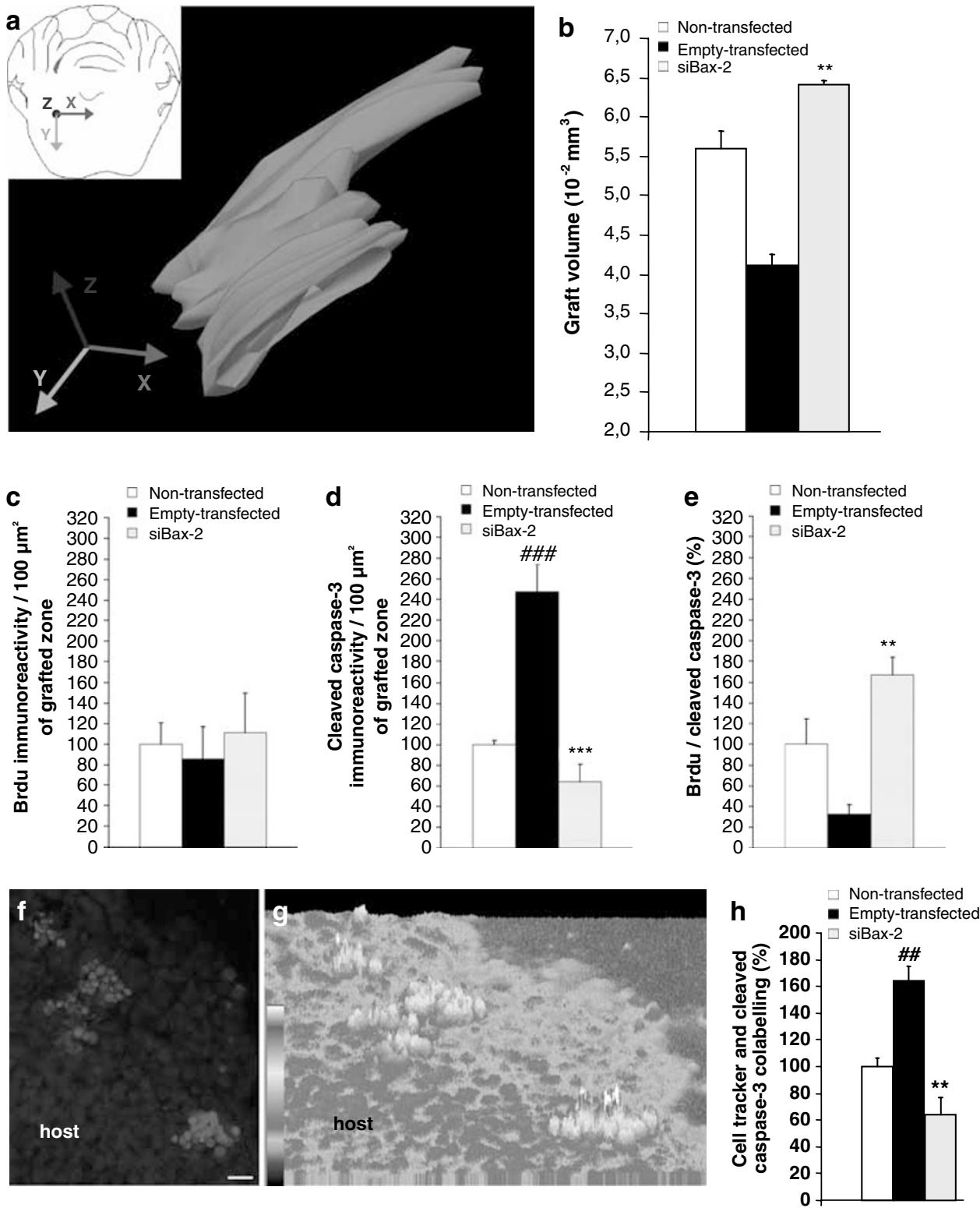

Figure 8 3D reconstruction of allografts, stereologic analysis of BrdU- and cleaved caspase-3 immunoreactive structures and threshold quantification of CellTracker ${ }^{\mathrm{TM}}$ Red positive cells immunoreactive for cleaved caspase-3. (a) Typical 3D reconstruction obtained in $24 \mathrm{~h}$ after the transplantation of empty-transfected precursors. Similar 3D reconstructions were obtained for each experimental group. (b) Volume of grafted structures in non-transfected, empty-transfected, and siBax-2-transfected experimental groups. (c) Density of BrdU-immunoreactive structures per $100 \mu \mathrm{m}^{2}$ of grafted zone in non-transfected, empty-transfected and siBax-2-transfected experimental groups. (d) Density of cleaved caspase-3 immunoreactive structures per $100 \mu \mathrm{m}^{2}$ of grafted zone in non-transfected, empty-transfected and siBax-2-transfected experimental groups. (e) BrdU/cleaved caspase-3 ratio quantified in grafted zones from non-transfected, empty-transfected and siBax-2 transfected experimental groups. (f and $\mathbf{g}$ ) Visualization of CellTracker ${ }^{\mathrm{TM}}$ Red-positive grafted cells (f) and the corresponding intensity diagram $(\mathbf{g})$ used to select the region of interest and quantify the fluorescence level by threshold. Fluorescence intensity in the host tissue was defined as the background level. Colour scale indicates low (blue) and high (red) intensities. (h) Percentage of CellTracker ${ }^{\mathrm{TM}}$ Red positive structures colabelled with cleaved caspase-3 in non-transfected, empty-transfected and siBax-2 transfected experimental groups. Each value represents the mean $\left( \pm\right.$ S.E.M.) of three independent experiments performed in duplicate. ${ }^{\#} P<0.01,{ }^{\# \# \#} P<0.001$ versus non-transfected cells; ${ }^{* \star} P<0.01,{ }^{* \star} P<0.001$ versus emptytransfected cells. A colour version of this Figure is available online

potential ability to survive and integrate into the host cell network. ${ }^{33}$ However, the majority of grafted precursors are subjected to death during the first hours following their transplantation. ${ }^{16}$ The death pathways activated upon allografting have not yet been completely understood. Proinflammatory cytokines, ${ }^{34}$ necrosis, ${ }^{35}$ and caspase-mediated apoptosis ${ }^{16,36,37}$ have been mentioned by different authors as a main reason of transplanted precursor cell death. Several strategies have been used to increase the yield of grafted cells survival. ${ }^{17,37,38}$ According to Cicchetti et al., ${ }^{17}$ simultaneous inhibition of caspases and complement system significantly improves survival of striatal neurons grafted into the rat brain. In a recent study, Niranjan et al. ${ }^{38}$ have shown that brain irradiation could facilitate subsequent survival of grafted 
neural progenitors in both normal and tumour-bearing brain through an unknown mechanism. On the other hand, the transplantation of immortalized neuronal precursors into the spinal cord may result in graft rejection even if immunosuppression had been performed. ${ }^{37}$ In the present study, we have observed that Bax repression strongly increases the total transplant volume in $24 \mathrm{~h}$ following their introduction. In addition, cleaved caspase-3 immunoreactivity was strongly reduced in siBax-transfected precursors, while density of grafted cells, which were visualized by BrdU, did not change in comparison to that of non-transfected precursors. Taken together, these data indicate that survival of precursors within the critical hours followed by their transplantation could be favoured by their transfection with siRNA interacting with Bax gene prior to transplantation.

This approach consisting in allotransplantation of precursors transfected by a specific siRNA has several advantages: (i), the treatment is targeted to a single specific gene and is thus focused on a particular mechanism, unlike the strategy of brain irradiation, ${ }^{38}$ (ii) the precursors stay in a modified state only within a limited time period, in contrast to the immortalized cells, ${ }^{37}$ and (iii) the transient apoptosis blockade, which also takes place in normal conditions in the regulation of cell cycle, may restrict some undesirable side-effects such as tumorigenesis. $^{39}$

In conclusion, our results indicate that Bax plays a key role in the apoptosis of immature granule neurons. In particular, the present data revealed that the ceramides represent a class of second messengers capable to stimulate Bax expression in vivo and, on the contrary, the downregulation of Bax expression using the siRNA approach represents a quite promising strategy to reduce death of transplanted neuronal precursors within the first hours following by their transplantation.

\section{Materials and Methods}

Animals. Wistar rats (Depré, Saint-Doulchard, France) were kept in a temperature-controlled room $\left(21 \pm 1^{\circ} \mathrm{C}\right)$ with an established photoperiod (the lights are on from 0700 to $1900 \mathrm{~h}$ ) with free access to food and tap water. Animal manipulations were performed according to the recommendations of the French Ethical Committee and under the supervision of authorized investigators.

Chemicals. C2-ceramide, 4',6-Diamidino-2-phenylindole (DAPI), dimethylsulphoxide (DMSO), fluoresceine diacetate (FDA), hydrogen peroxide, sodium dodecylsulphate (SDS), poly-L-lysine, 3,3'-diaminobenzidine (DAB), trypan blue, 5-bromo-2'-deoxyuridine (BrdU), the Ham's F12 nutrient mixture, N1 supplement, and the antibiotic/antimycotic solution $(10000 \mathrm{U} / \mathrm{ml}$ penicillin, $10 \mathrm{mg} / \mathrm{ml}$ streptomycin, $25 \mu \mathrm{g} / \mathrm{ml}$ amphotericin B) were from Sigma-Aldrich (Saint-Quentin Fallavier, France). The 38 amino-acid form of PACAP was provided by AF (PointeClaire, Canada). Bovine serum albumin (BSA; fraction V) was from Boehringer Mannheim (Meylan, France). Dulbecco's modified Eagle's medium (DMEM) was from Invitrogen (Cergy-Pontoise, France).

Immunohistochemical detection of Bax in cerebellum treated by C2-ceramide in vivo. Eight-day-old rats previously anesthetized by isoflurane inhalation were injected with $10 \mu \mathrm{l}$ of physiological saline $(0.9 \% \mathrm{NaCl})$ or $\mathrm{C} 2$ ceramide $(40 \mu \mathrm{M})$ using a $10-\mu \mathrm{l}$ Hamilton syringe. Control group rats were not injected at all. Four hours after the injection, animals were killed by decapitation, their cerebella were rapidly removed and frozen in isopentane at $-30^{\circ} \mathrm{C}$. Frozen cerebella were cut in the frontal plane into $12-\mu \mathrm{m}$-thick serial sections and post-fixed for $40 \mathrm{~min}$ in $0.1 \mathrm{M}$ PBS containing $4 \%$ paraformaldehyde. The sections were incubated overnight at $4^{\circ} \mathrm{C}$ in the presence of rabbit antibodies specific to Bax (sc493, Santa Cruz Biotechnology), which were diluted 1:200 in the incubation buffer
(PBS containing 1\% BSA and 3\% Triton X-100). After that, sections were rinsed for $30 \mathrm{~min}$ in PBS and then incubated with biotinylated goat anti-rabbit secondary antibodies (L42015, Caltag Laboratories, Burlingame, CA, USA) for $1 \mathrm{~h} 30 \mathrm{~min}$ at room temperature. Immunostaining signal has been amplified using an avidin-biotin complex (Vectastain, ABC kit Elite, Vector Laboratories, Biovalley, Conches, France) and then revealed using DAB and peroxidase substrate. Finally, the slices were rinsed in PBS, mounted with 1:1 (v/v) PBS:glycerol, coverslipped, and analyzed using a microscope (Nikon Eclipse E600) connected with a camera. Data were processed using Mercator software (Explora Nova). The specificity of immunoreaction was controlled by replacement of the Bax antibody by PBS.

Preparation and treatment of organotypic slices. Two 8-day-old rats were decapitated, their cerebella were removed and immediately placed into the ice-cold artificial cerebrospinal fluid containing (in $\mathrm{mM}$ ): $\mathrm{NaCl}, 125 ; \mathrm{KCl}, 3 ; \mathrm{CaCl}_{2}, 2$; $\mathrm{NaH}_{2} \mathrm{PO}_{4}, 1.2 ; \mathrm{MgSO}_{4}, 1.2 ; \mathrm{NaHCO}_{3}, 26$; D-Glucose 10; $\mathrm{pH}$ 7.4. $300 \mu \mathrm{M}$ transverse slices were cut at $4{ }^{\circ} \mathrm{C}$ using a vibratome (VT1000S; Leica) and transferred into 24well Costar plates containing a chemically defined medium consisting of $75 \%$ DMEM and 25\% Ham's F12 supplemented with $2 \mathrm{mM}$ glutamine, $1 \mathrm{mM}$ sodium pyruvate, $25 \mathrm{mM} \mathrm{KCl}, 1 \% \mathrm{~N}-1$ supplement $(\mathrm{X} 100)$, and $1 \%$ antibiotic-antimycotic solution. C2-ceramide (20 or $40 \mu \mathrm{M})$ and/or PACAP $\left(10^{-7} \mathrm{M}\right)$ were added to the wells containing slices, which were then incubated at $37^{\circ} \mathrm{C}$ for $4 \mathrm{~h}$ in a humidified incubator with an atmosphere of $5 \% \mathrm{CO}_{2} / 95 \%$ air. After that, proteins were extracted from slices and analyzed by western blot experiments.

Western blot analysis. Total proteins from cultured neurons or cerebellar organotypic slices were extracted in $900 \mu \mathrm{l}$ of lysis buffer (1\% Triton X-100, $10 \mathrm{mM}$ EDTA in $50 \mathrm{mM}$ Tris- $\mathrm{HCl}, \mathrm{pH} 6.8$ ) and analyzed by electrophoresis in $10 \%$ SDSPAGE system as previously described. ${ }^{11}$ After separation, proteins were electrically transferred onto a nitrocellulose membrane (Amersham Pharmacia), incubated with a Bax antibody raised in rabbit (sc-493, Santa Cruz Biotechnology), or a beta-actin antibody raised in mouse (sc-47778, Santa Cruz Biotechnology) and revealed using an ECL RPN 2108 chemiluminescence detection kit containing horseradish peroxidase-conjugated goat anti-rabbit or rabbit anti-mouse secondary antibodies (Amersham Pharmacia, Les Ulis, France). Autoradiographic films were quantified using an image analysis system (Samba, Grenoble, France).

Isolation and cultivation of cerebellar neuronal precursors. Granule cell suspensions were prepared from the cerebella of 8day-old rats as previously described. ${ }^{40}$ Briefly, neurons were cultured in a chemically defined medium consisting of 75\% DMEM and 25\% Ham's $\mathrm{F} 12$ supplemented with $25 \mathrm{mM} \mathrm{KCl}, 1 \% \mathrm{~N} 1$ supplement $(\times 100)$, and $1 \%$ antibioticantimycotic solution. Cells were grown at $37^{\circ} \mathrm{C}$ in a humidified incubator with an atmosphere of $5 \% \mathrm{CO}_{2} / 95 \%$ air. For subsequent studies by western blot or calcein/ ethidium assay, dispersed cells were seeded in 60-mm Falcon dishes (Becton Dickinson, Heidelberg, Germany) at a density of $4 \times 10^{3}$ cells per $\mathrm{mm}^{2}$. For cell survival quantification or caspase-3 activity measurement, cells were seeded in 24well plates (Costar, Cambridge, MA, USA) at a density of $2 \times 10^{3}$ cells per $\mathrm{mm}^{2}$. Prior to seeding, both dishes and plates were coated with $5 \mathrm{mM}$ poly-L-lysine solution.

Cell transfection. Precursors of granule neurons were transfected immediately after the preparation of cell suspension from 8-day-old rat cerebellum. An electroporation-based Amaxa Nucleofector technology together with a rat neuron nucleofection kit was used for this procedure (Amaxa Biosystems, Berlin, Germany). Two small interference RNAs (siRNAs) have been used, siBax-1 and siBax-2, whose sequences are 5'-CCGCGTGGTTGCCCTCTTCTA-3' (siBax1) and $5^{\prime}$-CTCCGGCGAATTGGAGATGAA-3', (siBax-2), which correspond to the Bax gene positions 324-344 and 187-207, respectively (GenBank accession no. NM_017059). Both siRNAs were synthesized chemically and supplied by Qiagen (Courtaboeuf, France). For each transfection procedure, $4 \times 10^{6}$ cells were centrifuged for $2 \mathrm{~min}$ at $100 \mathrm{~g}$ and then resuspended in $100 \mu \mathrm{l}$ of the transfection buffer, which had been pre-warmed at $37^{\circ} \mathrm{C}$. Fifteen micrograms of siBax-1 or siBax-2, previously dissolved in $20 \mu$ of the same buffer, was then added to cell suspension. Transfection was performed in special cuvettes supplied with kit. Transfected cells were then dissolved in $500 \mu \mathrm{l}$ of the culture medium (for subsequent cultivation in vitro), or centrifuged and resuspended in $10 \mu \mathrm{l} 0.9 \% \mathrm{NaCl}$ (for transplantation into the cerebella in vivo). For the transfection without siRNA (empty transfection), cells were subjected to the same procedures in the absence of any siRNA. For the transfection of neurons with GFP-expressing plasmid (used for 
visualization of the grafted precursors in a host cerebellum), $0.4 \mu \mathrm{g}$ of the pmaxGFP plasmid (VDF-1012; Amaxa Biosystems) was used in a procedure similar to the siRNA introduction.

Caspase-3 activity measurement. The activity of intracellular caspase-3 in neuronal precursors has been quantified after 6,12 and $24 \mathrm{~h}$ of cultivation using Apo-ONE ${ }^{\circledR}$ Homogeneous Caspase-3/7 Assay fluorometric system (Promega Corporation, Madison, WI, USA) according to the instruction manual. Briefly, hypotonic cell lysis buffer containing profluorescent caspase substrate Z-DEVDR110 was added to the cultivating cells, followed by incubation at $37^{\circ} \mathrm{C}$ for $3 \mathrm{~h}$. Fluorescence intensity was then measured using FlexStation II (Molecular Devices, Sunnyvale, CA, USA) at excitation and emission wavelengths of 485 and $520 \mathrm{~nm}$, respectively.

\section{Visualization of cell survival and death (calcein/ethidium assay). The survival of granule neuronal precursors was visualized after $24 \mathrm{~h}$ of their cultivation using the LIVE/DEAD ${ }^{\circledR}$ Viability/Cytotoxicity Kit for mammalian cells (Invitrogen, Cergy-Pontoise, France) according to the instruction manual. Briefly, cells were washed with PBS and then incubated for $20 \mathrm{~min}$ with the solution containing $2 \mu \mathrm{M}$ calcein (producing green fluorescence in living neurons) and $4 \mu \mathrm{M}$ ethidium homodimer (producing orange fluorescence in the nuclei of dead cells). Images were obtained and examined using a fluorescent videomicroscope system (Leica DM HRBE-Metamorph). Green fluorescence was visualized at the excitation and emission wavelengths 485 and $530 \mathrm{~nm}$; orange fluorescence at 530 and $585 \mathrm{~nm}$, respectively.}

Cell survival quantification. Quantification has been performed after 6,12 , and $24 \mathrm{~h}$ of neuronal precursors cultivation. Cells were incubated for $10 \mathrm{~min}$ with $15 \mu \mathrm{g}$ fluoresceine diacetate, which produces green fluorescence in living neurons. Afterwards, cells were washed with PBS and lysed by $5 \mathrm{mM}$ Tris- $\mathrm{HCl}$ solution $(\mathrm{pH}$ 6.8) containing $1 \%$ SDS. Fluorescence intensity was then measured using FlexStation II (Molecular Devices, Sunnyvale, CA, USA) at excitation and emission wavelengths of 485 and $520 \mathrm{~nm}$, respectively. Pilot experiments have shown that the fluorescence intensity is proportional to the number of living cells (in the range $2.5 \times 10^{2}-5 \times 10^{3}$ cells $/ \mathrm{mm}^{2}$ ) under those experimental conditions.

Optimization of stereotaxic coordinates for granule cell precursor injections into a rat cerebellum. Forty 8-day-old rats, previously anesthetized by isoflurane inhalation, were subjected to $2 \mu \mathrm{l}$ intracranial injections of $0.4 \%$ trypan blue solution in $0.81 \% \mathrm{NaCl} / 0.6 \% \mathrm{KCl}$ using a $10-\mu \mathrm{l}$ Hamilton syringe. In each case, the injection site was chosen randomly in the limits of $\pm 3 \mathrm{~mm}$ to each direction from the lambdoid suture. The depth of injections varied from 2 to $3 \mathrm{~mm}$. Each rat was decapitated immediately after trypan blue administration, and the injection point on the brain surface was detected visually. Trypan blue-positive cerebella were sliced into $12-\mu \mathrm{m}$ histological sections and observed under a light microscope to characterize the injection site positions. The following stereotaxic coordinates (relatively to the lambda structure) have been selected as optimal: AP $-1 \mathrm{~mm}, \mathrm{~L}-1 \mathrm{~mm}, \mathrm{DV}-3 \mathrm{~mm}$ (Figure $5 \mathrm{a}$ ). The injection point position on the brain surface is shown on Figure $5 \mathrm{~b}$. Histological analysis has revealed that the injection site is located nearby the border between the vermis (lobule IV) and the left cerebellar hemisphere (simple lobule; Figure $5 \mathrm{c}$ ). The prolonged shape of this zone corresponds to the pathway of an injecting needle.

Obtaining of primary neuronal precursors with BrdU-labeled nuclei. Eight-day-old rats were intracranially injected with $45 \mathrm{mg} / \mathrm{ml} \mathrm{BrdU}$ solution in phosphate-buffered saline (PBS) in the volume of $5 \mu \mathrm{l}$ per animal. Six hours later, rats were decapitated, and the suspension of granule neuronal precursors was prepared from their cerebella as described in the section 'Isolation and cultivation of cerebellar neuronal precursors'. Those precursors were then used for allotransplantation. To check whether BrdU is incorporated into the nuclei of precursors in the external granule cell layer, BrdU-treated cerebella were subjected to an immunohistochemical analysis followed by Cresyl violet staining.

Transplantation of BrdU-labeled precursors into rat cerebella. $4 \times 10^{6}$ immature granule cells with BrdU-labeled nuclei were transfected with Bax siRNA-2 or pure transfection buffer (empty transfection), followed by centrifugation $(2 \mathrm{~min}$ at $200 \mathrm{~g}$ ) and resuspension in $10 \mu \mathrm{l}$ of $0.9 \% \mathrm{NaCl}$. Then cells were immediately injected into the cerebella of two 8-day-old rats (i.e., $5 \mu$ l containing $2 \times 10^{6}$ cells per one animal) according to the selected stereotaxic coordinates indicated above. Twenty-four hours after injections, rats were decapitated, and their cerebella were removed and frozen in isopentane at $-30^{\circ} \mathrm{C}$. $12-\mu \mathrm{m}$-thick histological sections were then made using a freezing microtome for subsequent immunohistochemical procedures.

Immunohistochemical detection of BrdU and cleaved caspase3. Histological sections were fixed by $4 \%$ paraformaldehyde in $0.1 \mathrm{M}$ PBS for $40 \mathrm{~min}$, then DNA was denatured by treatment with $2 \mathrm{~N} \mathrm{HCl}$ in PBS $\left(45 \mathrm{~min}, 37^{\circ} \mathrm{C}\right)$. Afterwards, a protease pre-treatment was done using a solution containing $0.3 \%$ pepsin and $0.1 \%$ trypsin $\left(1 \mathrm{~h}, 37^{\circ} \mathrm{C}\right)$ to facilitate antibodies interaction with $\mathrm{BrdU}$ incorporated into DNA. Then sections were incubated with mouse anti-BrdU antibodies (B2531, Sigma-Aldrich) overnight at $+4^{\circ} \mathrm{C}$, rinsed with PBS for $30 \mathrm{~min}$ and incubated with biotinylated anti-mouse rat adsorbed secondary antibodies made in horse (BA-2001, Vector Laboratories) for $1 \mathrm{~h} 30 \mathrm{~min}$. Immunostaining signal was amplified using avidin-biotin complex (Vectastain, ABC kit Elite, Vector Laboratories) and revealed using DAB and peroxidase substrate. Visualization of cleaved caspase- 3 was done using adjacent sections of the cerebella in which grafted zones had been detected by BrdU-positive immunostaining. In this case, the immunohistochemical procedure was performed by the same protocol, from which stages of DNA denaturation and protease pre-treatment were excluded. The cleaved caspase-3 (Asp175) antibody was made in rabbit (\#9661, Cell Signaling Technology, Euromedex, Mudolsheim, France) and labelling revealed with biotinylated anti-rabbit secondary antibodies made in goat (L42015, Caltag Laboratories). For fluorescent immunohistochemistry, cleaved caspase-3 and BrdU immunostaining was performed in the same sections and revealed using, respectively, fluorescein isothiocyanate-conjugated (Goat) anti-rabbit IgG (GARFITC sc-2012) obtained from Santa Cruz Biotechnology (Santa Cruz, CA, USA) and Alexa Fluor ${ }^{\circledR}$ 594-conjugated (Goat) anti-mouse IgG (GAM-594 A11005) from Invitrogen (Cergy-Pontoise, France). For visualization of cell nuclei, the slices were incubated for $5 \mathrm{~min}$ with $1 \mu \mathrm{g} / \mathrm{ml}$ DAPI solution in PBS. Fluorescent signals were observed with a Leica epifluorescence microscope (Leica France, Rueil-Malmaison, France). For the cleaved caspase-3 labelling, specificity was controlled by immunohistochemistry and western blot after preincubation of the cleaved caspase3 antibody with its blocking peptide (No. 1050, Cell Signaling Technology) and by replacement of the antibody by PBS. Specificity of the BrdU labelling was controlled by immunohistochemistry in cerebellar slices from animals uninjected with BrdU and by replacement of the antibody by PBS.

Morphometric and ratiometric quantifications of caspase-3 cleavage. Histological sections stained with anti-BrdU and anticleaved caspase-3 antibodies were observed under the light microscope Nikon Eclipse E600 (Nikon, Champigny-sur-Marne, France) connected with camera for image registration. The zones containing allografted precursors were detected by BrdUpositive immunostaining. For measurement of graft volumes, the images of histological slices were obtained at the standardized conditions (magnification, brightness) and saved in TIFF format using a computer-assisted image analysis station (Mercator, Explora Nova, La Rochelle, France). Afterwards, the RO corresponding to the BrdU-positive immunostaining zones were selected, and their areas were quantified using the Mercator software. Data obtained from each section were integrated to calculate the volume and to realize the $3 \mathrm{D}$ reconstruction.

For quantification of caspase- 3 cleavage in the grafted cells, ratiometric and stereological approaches were employed using the software Mercator Pro version V1.85 (Explora nova, la Rochelle, France). A counting frame was defined within the $\mathrm{ROI}$ and a threshold was set to distinguish the positive BrdU immunostaining from the background. Number and total area of positive objects within the ROI was calculated by a segmentation process. Cleaved caspase- 3 was quantified similarly, then the ratio BrdU/cleaved caspase- 3 was calculated within each graft. The quantification was performed by such way on 8-12 slices per animal depending of the graft size.

Quantification of the CellTracker ${ }^{\mathrm{TM}}$ Red-positive grafted cells colabelled with the cleaved caspase-3.. CellTracker ${ }^{\mathrm{TM}}$ Red (Invitrogen, Molecular probes, Cergy-Pontoise, France) was used to identify the grafted granule cell precursors and to quantify the cleaved caspase- 3 immunoreactivity associated with these grafted precursors. Practically, $6 \times 10^{6}$ granule cell precursors were incubated for $15 \mathrm{~min}$ within $1 \mathrm{ml}$ of chemically defined medium containing the fluorescent dye $(10 \mu \mathrm{M})$. Afterwards, cells were washed by centrifugation ( $2 \mathrm{~min}$ at $200 \mathrm{~g}$ ) and submitted or not to transfection with siBax-2 prior their grafts. Pilot experiments performed in vitro indicated that approximately $70 \%$ of the precursors 
were labelled by the dye (data not shown). Twenty - four hours after engraftment cerebella were removed, sliced and submitted to cleaved caspase-3 immunohistochemistry. CellTracker ${ }^{\mathrm{TM}}$ Red-positive cells were identified in the histological sections using a light microscope Leica DM equipped with the image analysis software Metamorph (Roper Scientific, Evry, France). The fluorescence intensity profile was used to define the ROI corresponding to the CellTracker ${ }^{\mathrm{TM}}$ Redpositive cells. Percentage of colabelling was quantified by measuring the cleaved caspase-3 immunoreactivity in the ROI. For each fluorescent signal, CellTracker ${ }^{\mathrm{TM}}$ (red) and cleaved caspase-3 (green), a background level was defined in a negative region of the host tissue.

Statistical analysis. Data are presented as the mean \pm S.E.M. of at least three independent experiments each performed at least in duplicate. Statistical analysis of the data was performed by using an ANOVA followed by Tukey's post hoc test.

Acknowledgements. This work was supported by INSERM (U413), the Fondation de la Recherche Médicale, the Regional Platform for Cell Imaging and the Conseil Régional de Haute-Normandie. We thank Mr Gérard Cauchois, Mrs Huguette Lemonnier and Mrs Colette Piard for skillfull technical assistance. SZ was the recipient of a fellowship from the Fondation pour la Recherche Médicale. AD is a recipient of a fellowship from the Ministère de la Recherche. HV is affiliated professor at the INRS-Institut Armand-Frappier.

1. Haydar TF, Kuan CY, Flavell RA, Rakic $P$. The role of cell death in regulating the size and shape of the mammalian forebrain. Cereb Cortex 1999; 9: 621-626.

2. Pompl PN, Yemul S, Xiang Z, Ho L, Haroutunian V, Purohit D et al. Caspase gene expression in the brain as a function of the clinical progression of Alzheimer disease. Arch Neurol 2003; 60: 369-376.

3. Lanave C, Santamaria M, Saccone C. Comparative genomics: the evolutionary history of the Bcl-2 family. Gene 2004; 33: 71-79.

4. Rosse T, Olivier R, Monney L, Rager M, Conus S, Fellay I et al. Bcl-2 prolongs cell surviva after bax-induced release of cytochrome c. Nature 1998; 391: 496-499.

5. Walensky LD. BCL-2 in the crosshairs: tipping the balance of life and death. Cell Death Differ 2006; 13: 1339-1350

6. Korsmeyer SJ, Wei MC, Saito M, Weiler S, Oh KJ, Schlesinger PH. Pro-apoptotic cascade activates BID, which oligomerizes BAK or BAX into pores that result in the release of cytochrome c. Cell Death Differ 2000; 7: 1166-1173.

7. Kamradt MC, Chen F, Cryns VL. The small heat shock protein $\alpha$ B-crystallin negatively regulates cytochrome $c$ - and caspase-8-dependent activation of caspase- 3 by inhibiting its autoproteolytic maturation. J Biol Chem 2001; 276: 16059-16063.

8. Kuida K, Lippke JA, Ku G, Harding MW, Livingston DJ, Su MS et al. Altered cytokine export and apoptosis in mice deficient in interleukin-1 beta converting enzyme. Science 1995; 267: 2000-2003.

9. Kuida K, Zheng TS, Na S, Kuan C, Yang D, Karasuyama $\mathrm{H}$ et al. Decreased apoptosis in the brain and premature lethality in CPP32-deficient mice. Nature 1996; 384: 368-372.

10. Miyata A, Jiang L, Dahl RD, Kitada C, Kubo K, Fujino M et al. Isolation of a neuropeptide corresponding to the $\mathrm{N}$-terminal 27 residues of the pituitary adenylate cyclase - activating polypeptide with 38 residues (PACAP38). Biochem Biophys Res Commun 1990; 170: 643-648.

11. Falluel-Morel A, Aubert N, Vaudry D, Basille M, Fontaine M, Fournier A et al. Opposite regulation of the mitochondrial apoptotic pathway by $\mathrm{C} 2$-ceramide and PACAP through a MAP-kinase-dependent mechanism in cerebellar granule cells. J Neurochem 2004; 91: 1231-1243.

12. Aubert N, Falluel-Morel A, Vaudry D, Xifro X, Rodriguez-Alvarez J, Fisch C et al. PACAP and $\mathrm{C} 2$-ceramide generate different AP-1 complexes through a MAP-kinase-dependent pathway: involvement of c-Fos in PACAP-induced Bcl-2 expression. J Neurochem 2006 99: $1237-1250$

13. Stoffel W, Jenke B, Block B, Zumbansen M, Koebke J. Neutral sphingomyelinase 2 (smpd3) in the control of postnatal growth and development. Proc Natl Acad Sci USA 2005; 102: 4554-4559.

14. Oh HL, Seok JY, Kwon CH, Kang SK, Kim YK. Role of MAPK in ceramide-induced cell death in primary cultured astrocytes from mouse embryonic brain. Neurotoxicology 2006; 27: 31-38.

15. Fischer I. Candidate cells for transplantation into the injured CNS. Prog Brain Res 2000; 128: 253-257.
16. Bakshi A, Keck CA, Koshkin VS, LeBold DG, Siman R, Snyder EY et al. Caspase-mediated cell death predominates following engraftment of neural progenitor cells into traumatically injured rat brain. Brain Res 2005; 1065: 8-19.

17. Cicchetti F, Costantini L, Belizaire R, Burton W, Isacson O, Fodor W. Combined inhibition of apoptosis and complement improves neural graft survival of embryonic rat and porcine mesencephalon in the rat brain. Exp Neurol 2002; 177: 376-384.

18. Toman RE, Movsesyan V, Murthy SK, Milstien S, Spiegel S, Faden Al. Ceramide-induced cell death in primary neuronal cultures: upregulation of ceramide levels during neuronal apoptosis. J Neurosci Res 2002; 68: 323-330.

19. Vaudry D, Falluel-Morel A, Basille M, Pamantung TF, Fontaine M, Fournier A et al. Pituitary adenylate cyclase-activating polypeptide prevents $\mathrm{C} 2$-ceramide-induced apoptosis of cerebellar granule cells. J Neurosci Res 2003; 72: 303-316.

20. Schelman WR, Andres RD, Sipe KJ, Kang E, Weyhenmeyer JA. Glutamate mediates cell death and increases the Bax to Bcl-2 ratio in a differentiated neuronal cell line. Mol Brain Res 2004; 128: 160-169.

21. Kurinna S, Konopleva M, Palla SL, Chen W, Kornblau S, Contractor R et al. Bcl2 phosphorylation and active PKC alpha are associated with poor survival in AML. Leukemia 2006; 20: 1316-1319.

22. Herget T, Esdar C, Oehrlein SA, Heinrich M, Schutze S, Maelicke A et al. Production of ceramides causes apoptosis during early neural differentiation in vitro. J Biol Chem 2000; 275: 30344-30354.

23. Caricchio R, D'Adamio L, Cohen PL. Fas, ceramide and serum withdrawal induce apoptosis via a common pathway in a type II Jurkat cell line. Cell Death Differ 2002; 9: 574-580.

24. Kolesnick R, Fuks Z. Radiation and ceramide-induced apoptosis. Oncogene 2003; 22 : 5897-5906.

25. Castiglione M, Spinsanti P, lacovelli L, Lenti L, Martini F, Gradini R et al. Activation of Fas receptor is required for the increased formation of the disialoganglioside GD3 in cultured cerebellar granule cells committed to apoptotic death. Neuroscience 2004; 126: 889-898.

26. Kumar S. Caspase function in programmed cell death. Cell Death Differ 2007; 14: 32-43.

27. Ward MW, Rehm M, Duessmann H, Kacmar S, Concannon CG. Prehn JH. Real time single cell analysis of Bid cleavage and Bid translocation during caspase-dependent and neuronal caspase-independent apoptosis. J Biol Chem 2006; 281: 5837-5844.

28. Phillips DC, Martin S, Doyle BT, Houghton JA. Sphingosine-induced apoptosis in rhabdomyosarcoma cell lines is dependent on pre-mitochondrial Bax activation and postmitochondrial caspases. Cancer Res 2007; 67: 756-764.

29. Alton M, Taketo T. Switch from BAX-dependent to BAX-independent germ cell loss during the development of fetal mouse ovaries. J Cell Sci 2007; 120: 417-424.

30. Namura S, Zhu J, Fink K, Endres M, Srinivasan A, Tomaselli KJ et al. Activation and cleavage of caspase-3 in apoptosis induced by experimental cerebral ischemia. $J$ Neurosci 1998; 18: 3659-3668.

31. Lakhani SA, Masud A, Kuida K, Porter GA, Booth CJ, Mehal WZ et al. Caspases 3 and 7 : key mediators of mitochondrial events of apoptosis. Science 2006; 311: 847-851.

32. White FA, Keller-Peck CR, Knudson CM, Korsmeyer SJ, Snider WD. Widespread elimination of naturally occurring neuronal death in Bax-deficient mice. J Neurosci 1998; 18: $1428-1439$.

33. Muraoka K, Shingo T, Yasuhara T, Kameda M, Yuan W, Hayase $\mathrm{H}$ et al. The high integration and differentiation potential of autologous neural stem cell transplantation compared with allogeneic transplantation in adult rat hippocampus. Exp Neurol 2006; 199: 311-327.

34. Tullius SG, Nieminen-Kelha M, Buelow R, Reutzel-Selke A, Martins PN, Pratschke J et al. Inhibition of ischemia/reperfusion injury and chronic graft deterioration by a single-donor treatment with cobalt-protoporphyrin for the induction of heme oxygenase-1. Transplantation 2002; 74: 591-598.

35. Emgard M, Hallin U, Karlsson J, Bahr BA, Brundin P, Blomgren K. Both apoptosis and necrosis occur early after intracerebral grafting of ventral mesencephalic tissue: a role for protease activation. J Neurochem 2003; 86: 1223-1232.

36. Hurelbrink CB, Armstrong RJ, Luheshi LM, Dunnet SB, Rosser AE, Barker RA. Death of dopaminergic neurons in vitro and in nigral grafts: re-evaluating the role of caspase activation. Exp Neurol 2001; 171: 46-58.

37. Li P, Tessier A, Han SS, Fischer I, Rao MS, Selzer ME. Fate of immortalized human neuronal progenitor cells transplanted in rat spinal cord. Arch Neurol 2005; 62: 223-229.

38. Niranjan A, Fellows W, Stauffer W, Burton EA, Hong CS, Lunsford LD et al. Survival of transplanted neural progenitor cells enhanced by brain irradiation. J Neurosurg 2007; 107 : 383-391.

39. Shih CC, Forman SJ, Chu P, Slovak M. Human Embryonic Stem cells are prone to generate primitive, undifferentiated tumors in engrafted human fetal tissues in severe combined immunodeficient mice. Stem Cells Dev 2007; 16: 893-902.

40. Gonzalez B, Leroux P, Lamacz M, Bodenant C, Balazs R, Vaudry H. Somatostatin receptors are expressed by immature cerebellar granule cells: evidence for a direct inhibitory effect of somatostatin on neuroblast activity. Proc Natl Acad Sci USA 1992; 89: 9627-9631. 